\title{
Hyperinsulinaemia is not a major coronary risk factor in elderly men
}

\section{The Study of Men Born in 1913}

\author{
L. Welin ${ }^{1}$, H. Eriksson ${ }^{1}$, B. Larsson ${ }^{2}$, L.-O. Ohlson ${ }^{2}$, K.Svärdsudd $^{3}$ and G.Tibblin $^{3}$ \\ ${ }^{1}$ Department of Medicine, Östra Hospital ${ }^{2}$ Department of Medicine, Sahlgrenska Hospital, University of Göteborg, Gothenburg and \\ ${ }^{3}$ the Department of Family Medicine, Uppsala University, Uppsala, Sweden
}

\begin{abstract}
Summary. Insulin and insulin resistance have attracted considerable interest as possible risk factors for coronary heart disease during the last decade. We therefore examined the 8year incidence of coronary heart disease in 59567 -year-old men in relation to baseline insulin and other risk factors. The incidence of coronary heart disease increased from $9 \%$ among non-diabetic men to $13.5 \%$ among those with impaired glucose tolerance, $12.9 \%$ among newly-detected diabetic men and up to $31.3 \%$ among men with known diabetes. The incidence of coronary heart disease was related to fasting blood glucose and $1 \mathrm{~h}$ and $2 \mathrm{~h}$ blood glucose during the oral glucose tolerance test and to serum cholesterol and serum triglycerides. Fasting serum insulin was of borderline significance for the risk of coronary heart disease. When known diabetic subjects were excluded only serum cholesterol and serum triglycerides remained as statistically signifi-
\end{abstract}

cant risk factors. Among diabetic subjects (known and newly-detected) only blood glucose was related to the risk of coronary heart disease. In multivariate analyses the different degrees of glucose intolerance or fasting blood glucose were independently related to the risk of coronary heart disease $(p=0.008-0.010)$. Serum triglycerides were also an independent risk factor in three out of four multivariate models $(p=0.02-0.09)$. Fasting serum insulin was not an independent risk factor. These findings do not support the hypothesis that hyperinsulinaemia is a major risk factor for coronary heart disease in elderly men. Hyperglycaemia (or diabetes mellitus) seems to be the most important risk factor.

Key words: Coronary heart disease incidence, men, insulin, glucose, diabetes mellitus, cholesterol, triglycerides.
There has been an increasing interest in insulin and insulin resistance as possible major risk factors for coronary heart disease (CHD) and as a major component of a metabolic syndrome accelerating the atherosclerotic process [1].

Hyperinsulinaemia is associated with other CHD risk factors, notably hypertriglyceridaemia, low HDL levels, hypertension, hyperglycaemia and abdominal obesity [2]. There is little evidence of a relationship between hyperinsulinaemia and the two other major CHD risk factors, hypercholesterolaemia and smoking habits [3]. Clinical, epidemiological and experimental evidence indicates that insulin has a direct and causal role in the development of atherosclerosis [2].

Numerous articles from prospective epidemiological studies have firmly established that hypercholesterolaemia, hypertension and smoking are the three major CHD risk factors. Three prospective studies [3-5] have shown a positive association between plasma (or serum) insulin and the incidence of CHD in male subjects, but no such association was found in female subjects [4]. In borderline diabetic subjects an inverse relationship between plasma insulin ( $2 \mathrm{~h}$ after $50 \mathrm{~g}$ oral glucose) and cardiovascular events was found [6].

Diabetes mellitus increases the risk of CHD two- to three-fold in male subjects $[7,8]$ while impaired glucose tolerance increases the risk two-fold [9].

There is a need for further prospective studies analysing the relationship between hyperinsulinaemia and CHD [2] especially among the elderly since there is a lack of information in this age group. We have therefore analysed the relationship between insulin, diabetes and other CHD risk factors in relation to the incidence of $\mathrm{CHD}$ during 8 years of follow-up in a prospective population study of elderly men.

\section{Subjects and methods}

\section{Study population}

The Study of Men Born in 1913 is a prospective cohort study which started in 1963 [10]. The men have been re-examined in 1967, 1973, 1980 and 1988. At each examination men living in Gothenburg and 
Table 1. Mean values of coronary heart disease risk factors in relation to the different degrees of glucose intolerance

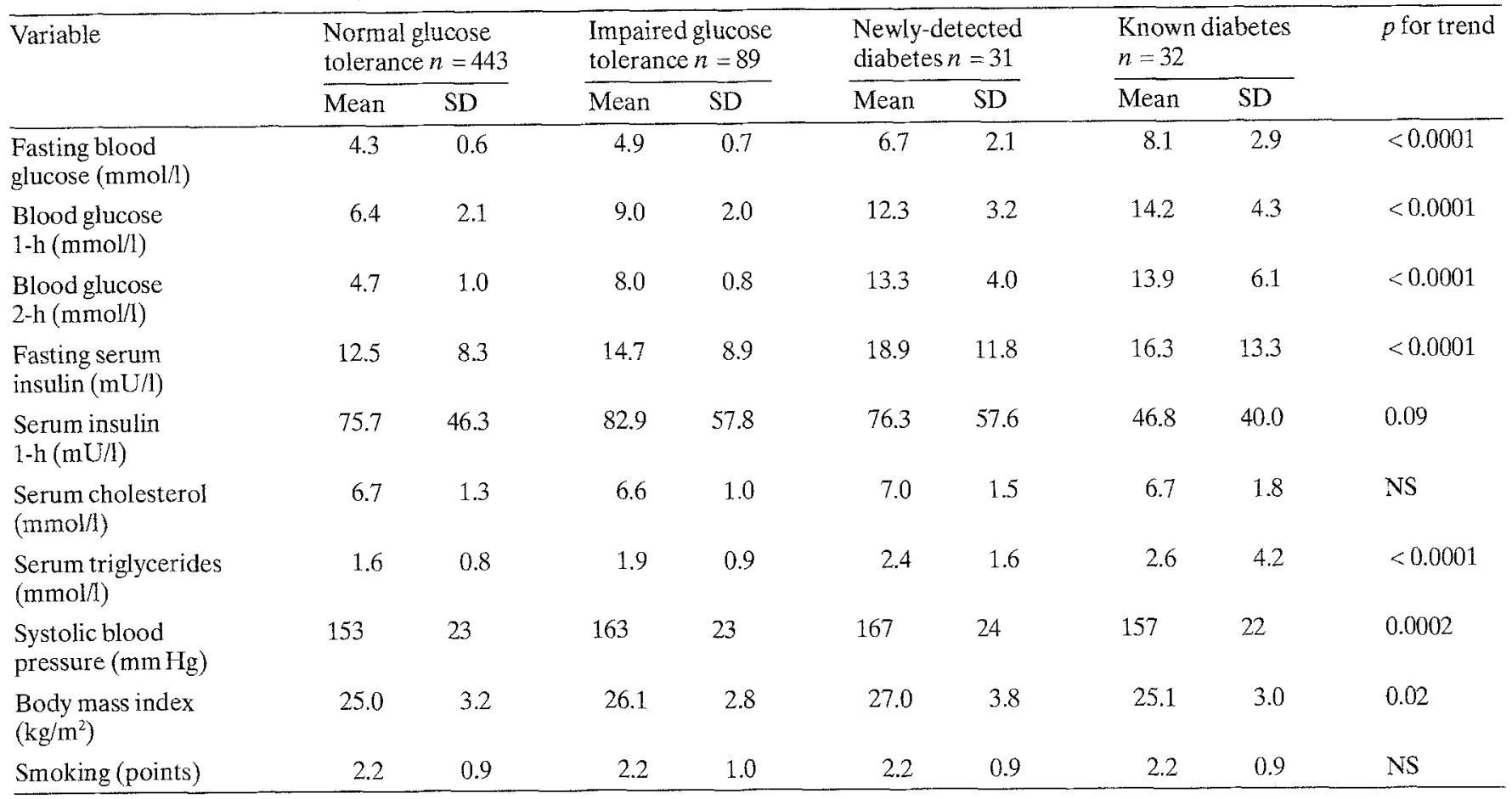

born in 1913 on dates divisible by three (i. e. the $3 \mathrm{rd}, 6$ th, 9 th etc. of each month) have been invited to participate.

The baseline for the present study is the examination in 1980 when 64467-year-old men from a population sample in Gothenburg were examined ( $79 \%$ participation rate). The population has been described previously in detail [11]. Ethical committee approval was obtained from the University of Göteborg.

\section{Baseline data}

The men were examined the morning after an overnight fast. Venous blood samples were drawn for serum cholesterol, serum triglyceride and whole blood glucose (automated routine biochemical methods) determinations. Subfractions of cholesterol were not measured. Serum insulin was determined by a double antibody method using a commercially available radioimmunoassay kit (Phadebas; Pharmacia, Uppsala, Sweden). A $100 \mathrm{~g}$ oral glucose tolerance test (OGTT) was performed and blood glucose measured before, and 1 and $2 \mathrm{~h}$ after the glucose load. A tolerance test of $100 \mathrm{~g}$, instead of $75 \mathrm{~g}$, was performed in order to use the same method as used at the examination in 1973. Others have shown that in the elderly the difference between $75 \mathrm{~g}$ and $100 \mathrm{~g}$ seems to be of minor importance [12]. Serum insulin was measured before and $1 \mathrm{~h}$ after the OGTT. Participants treated with insulin and those who had undergone major gastric surgery were exempt from the OGTT. Diabetes was defined according to the World Health Organization (WHO) criteria [13] i.e. known diabetes or fasting whole venous blood glucose greater than or equal to $6.7 \mathrm{mmol} / \mathrm{h}$ or $2-\mathrm{h}$ whole venous blood glucose greater than or equal to $10.0 \mathrm{mmol} / 1$. Impaired glucose tolererence (IGT) was defined as fasting blood glucose less than $6.7 \mathrm{mmol} / \mathrm{l}$ and 2 -h blood glucose between $6.7-9.9 \mathrm{mmol} / 1$. Those who had been informed that they had diabetes were classified as known diabetic subjects. All others, including those with missing data, were classified as normal. A detailed description has been published [11] with the WHO criteria from 1980 [14] used for classification of diabetes and IGT:

Fasting serum insulin was used to measure the insulin resistance [15]. Body weight was measured with a balance scale to the nearest
$0.1 \mathrm{~kg}$, the men wearing light clothes only. Height was measured to the nearest cm without shoes. The body mass index was calculated as weight (in $\mathrm{kg}$ ) divided by the height in $\mathrm{m}^{2}$. Blood pressure was recorded in the right arm, with the subject seated and after a 5-min interview, using a mercury sphygmomanometer with cuff size $12 \times 23 \mathrm{~cm}$. Smoking habits were coded as follows: $1=$ never smoked, $2=$ ex-smokers, $3=$ smoking $1-14$ g/day, $4=$ smoking 15 $24 \mathrm{~g} /$ day, $5=$ smoking $>24 \mathrm{~g} /$ day. One cigarette was assumed to be equivalent to $1 \mathrm{~g}$ of tobacco, one cheroot to $2 \mathrm{~g}$, and one cigar to $5 \mathrm{~g}$. Pipe smokers were classified according to their average daily tobacco consumption.

\section{Follow-up and end-points}

In 1988 all participants were followed-up by examination or through postal questionnaires, scrutiny of hospital and out-patient records both in Gothenburg and other counties (if the participant had moved) and through the mortality register of the Central Bureau of Statistics. Follow-up with respect to the end-point CHD was $100 \%$.

The end-point CHD, is defined as a fatal or non-fatal myocardial infarction (MI) or death from CHD (when other causes of death could be ruled out). Criteria for MI have been published [16]. Angina pectoris is not considered an end-point in this report nor are ECG changes.

\section{Statistical analyses}

All analyses were performed with the Statistical Analyses System [17] at the Gothenburg Computer Centre. Serum triglyceride and serum insulin distributions were highly skewed towards high values so $\log$ transformation (natural logarithm) was used in the analyses but arithmetic means are presented in the Tables. Student's $t$-test was used to analyse differences in mean values. Trends in proportions were tested with Pitman's non-parametric permutation test [18]. For multivariate analyses, the multiple logistic regression technique was used. All statistical tests were two-tailed. 


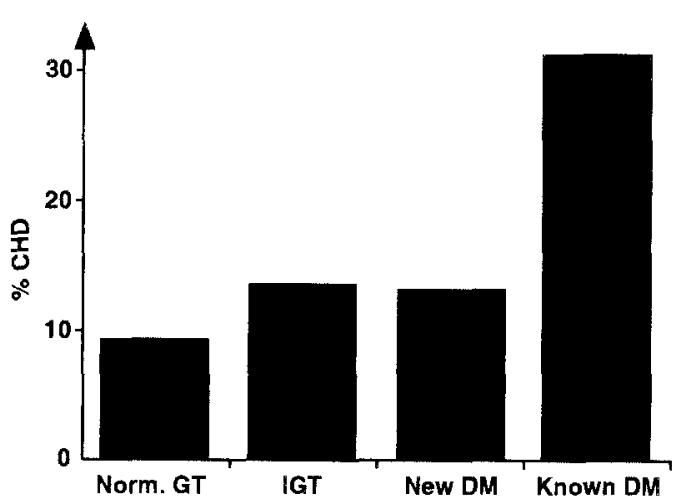

Fig. 1. The incidence of coronary heart disease (CHD) during 8 years of follow-up among men with normal glucose tolerance (Norm. GT) $(n=443)$, with impaired glucose tolerance (IGT) $(n=89)$ with newly-detected diabetes (new Dm) $(n=31)$ and with known diabetes (known Dm) $(n=32)$. The trend is significant $(p=0.001)$

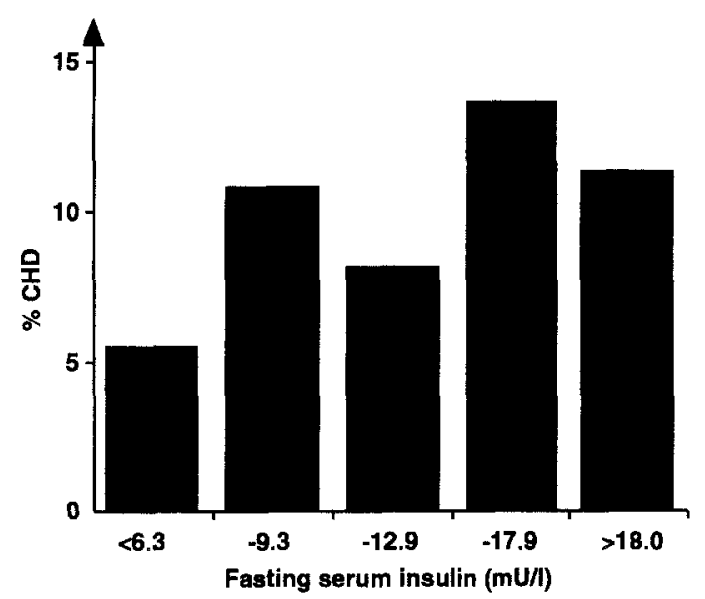

Fig. 2. The incidence of coronary heart disease (CHD) during 8 years of follow-up in men grouped according to quintiles of fasting serum insulin (known diabetic subjects excluded). The trend is not statistically significant $(p=0.12)$

\section{Results}

Among the 644 67-year-old men who participated in the study 49 had already had an MI before the baseline examination. This left 595 men at risk of a first CHD event and $66(11.1 \%)$ of these men developed CHD during the 8 years of follow-up.

Sixty-three $(10.6 \%)$ of the 595 men had diabetes ( 32 were known and 31 were detected at the examination), 89 were classified as having IGT and 443 had a normal glucose tolerance. Among the known diabetic subjects 18 were treated with insulin, 8 were treated with oral hypoglycaemic tablets and diet and 6 were treated with diet only.

Mean values of CHD risk factors in the four glucose tolerance groups are listed in Table 1 . Fasting, $1 \mathrm{~h}$ and $2 \mathrm{~h}$ blood glucose increased significantly with increasing degrees of glucose intolerance. Fasting serum insulin also increased with increasing degrees of glucose intolerance but known diabetic subjects had a slightly lower mean level than newly-detected diabetic subjects. Subjects with IGT had the highest $1 \mathrm{~h}$ serum insulin and known diabetic sub- jects had the lowest $1 \mathrm{~h}$ serum insulin level. Among the other CHD risk factors serum triglycerides, systolic blood pressure and body mass index increased with increasing degree of glucose intolerance while cholesterol and smoking did not.

The 8-year incidence of CHD increased from $9.0 \%$ among those with normal glucose tolerance to $13.5 \%$ among those with IGT, to $12.9 \%$ among those with newlydetected diabetes and up to $31.3 \%$ among those with known diabetes (Fig.1, $p=0.001$ ). Among known diabetic subjects there was no statistically significant relation between the duration of the disease and the incidence of CHD. Insulin-treated diabetic subjects tended to have a higher incidence of CHD (39\%) than the other known diabetic subjects $(21 \%, p=0.25)$.

In Table 2 participants with and without CHD during 8 years of follow-up are compared. Fasting blood glucose, $1 \mathrm{~h}$ and $2 \mathrm{~h}$ blood glucose as well as serum cholesterol and serum triglycerides were all significantly related to the incidence of CHD (left part of Table 2). Fasting serum insulin was of borderline significance. If known diabetic subjects are excluded (right part of Table 2) only serum cholesterol and serum triglycerides remained as statistically significant $\mathrm{CHD}$ risk factors. In the diabetic group (known and newly-detected) there was a significant association between fasting blood glucose and the risk of CHD (CHD cases 8.8 \pm 3.0 , non-cases $7.0 \pm 2.4, p=0.02$, not shown in Table 2).

In our cohort fasting serum insulin increases with increasing degree of glucose tolerance, newly-detected diabetic subjects having the highest levels. We therefore analysed fasting serum insulin levels divided into quintiles in relation to the incidence of CHD after exclusion of known diabetic patients (this was also done in order to compare our findings with the Paris Prospective Study, [5]). There was a non-significant tendency towards an increasing risk of $\mathrm{CHD}$ with increasing fasting serum insulin levels (Fig. 2).

The variables which were significantly related to the incidence of CHD in univariate analyses were entered into a multiple logistic regression (Table 3 ). Fasting blood glucose or degree of glucose intolerance (referred to as diabetes in Table 3) then emerged as the strongest predictors of CHD in the two models in which it was used. Fasting serum insulin, $1 \mathrm{~h}$ and $2 \mathrm{~h}$ blood glucose and serum cholesterol were not predictive of CHD. Serum triglycerides were predictive of CHD in three of the four models.

\section{Discussion}

It is important to note that our participants were elderly men ( 67 years) at the baseline examination. We have found a weak but non-significant association between hyperinsulinaemia and the risk of CHD. There may be two reasons for this finding; 1 . Our study is too small and thus lacks the power to detect a true relationship between hyperinsulinaemia and the risk of CHD. The Paris Prospective Study was 10 times larger than our study and found a significant association between fasting insulin and the risk of CHD [5]. 2. Hyperinsulinaemia may well be an 
Table 2. Mean values of coronary heart disease (CHD) risk factors by subsequent incidence of CHD during 8 years of follow-up. The left part of the table includes all participants. In the right part of the table subjects with known diabetes have been excluded

\begin{tabular}{|c|c|c|c|c|c|c|c|c|c|c|}
\hline \multirow[t]{3}{*}{ Risk factor } & \multicolumn{4}{|c|}{ All participants } & \multirow{3}{*}{$p$} & \multicolumn{4}{|c|}{ Known diabetic subjects excluded } & \multirow{3}{*}{$p$} \\
\hline & \multicolumn{2}{|c|}{ NoCHD $n=529$} & \multicolumn{2}{|c|}{$\mathrm{CHD} n=66$} & & \multicolumn{2}{|c|}{ No CHD $n=507$} & \multicolumn{2}{|c|}{ CHD $n=56$} & \\
\hline & Mean & SD & Mean & $\mathrm{SD}$ & & Mean & $\mathrm{SD}$ & Mean & $\overline{\mathrm{SD}}$ & \\
\hline $\begin{array}{l}\text { Fasting blood } \\
\text { glucose }(\mathrm{mmol} / \mathrm{l})\end{array}$ & 4.7 & 1.2 & 5.4 & 2.4 & 0.0008 & 4.5 & 0.9 & 4.7 & 1.4 & NS \\
\hline $\begin{array}{l}\text { Blood glucose } \\
\text { 1-h (mmol/1) }\end{array}$ & 7.3 & 2.9 & 8.4 & 4.4 & 0.02 & 7.1 & 2.6 & 7.4 & 3.5 & NS \\
\hline $\begin{array}{l}\text { Blood glucose } \\
\text { 2-h (mmol/1) }\end{array}$ & 5.9 & 2.9 & 7.2 & 4.9 & 0.006 & 5.6 & 2.3 & 5.9 & 3.3 & NS \\
\hline $\begin{array}{l}\text { Fasting serum } \\
\text { insulin (mU/l) }\end{array}$ & 13.2 & 9.1 & 15.0 & 9.0 & 0.05 & 13.0 & 8.8 & 14.6 & 9.0 & 0.2 \\
\hline $\begin{array}{l}\text { Serum insulin } \\
1-\mathrm{h}(\mathrm{mU} / \mathrm{l})\end{array}$ & 74.9 & 47.5 & 81.1 & 60.0 & NS & 75.8 & 47.4 & 86.3 & 61.0 & 0.1 \\
\hline $\begin{array}{l}\text { Serum cholesterol } \\
(\mathrm{mmol} / \mathrm{l})\end{array}$ & 6.7 & 1.3 & 7.1 & 1.4 & 0.009 & 6.7 & 1.2 & 7.1 & 1.3 & 0.02 \\
\hline $\begin{array}{l}\text { Serum triglycerides } \\
(\mathrm{mmol} / \mathrm{)})\end{array}$ & 1.6 & 0.9 & 2.4 & 3.1 & 0.0002 & 1.6 & 0.9 & 2.0 & 1.1 & 0.008 \\
\hline $\begin{array}{l}\text { Systolic blood } \\
\text { pressure (mm Hg) }\end{array}$ & 155 & 23 & 156 & 25 & NS & 155 & 23 & 156 & 25 & $\mathrm{NS}$ \\
\hline $\begin{array}{l}\text { Body mass index } \\
\left(\mathrm{kg} / \mathrm{m}^{2}\right)\end{array}$ & 25.3 & 3.2 & 25.5 & 3.5 & NS & 25.3 & 3.2 & 25.4 & 3.5 & $\mathrm{NS}$ \\
\hline Smoking (points) & 2.2 & 0.9 & 2.3 & 0.9 & NS & 2.2 & 0.9 & 2.3 & 1.0 & $\mathrm{NS}$ \\
\hline
\end{tabular}

Statistical analysis was performed after log transformation of insulin and triglycerides but values are given as arithmetic means

important risk factor for CHD in young and middle-aged men and those who are susceptible die before the age of 67 years. We may then be left with a cohort of elderly men resistant to the deleterious effects of hyperinsulinaemia and insulin resistance. Insulin resistance may not be the secret killer among elderly men as has been suggested for middle-aged men [19].

On the other hand, these elderly men may still be sensitive to the harmful effects of hyperglycaemia. This effect of hyperglycaemia on the risk of CHD is mainly confined to the subgroup of men with known diabetes. When known diabetic subjects are excluded there is no longer any statistical association between blood glucose and the risk of CHD.

We have recently published our results concerning blood lipids as risk factors for CHD [20]. Hypertriglyceridaemia was the major CHD risk factor in elderly men but blood glucose was not included in the analyses. In another larger Swedish study of middle-aged men [7] it was shown that increased serum cholesterol was an independent risk factor for $\mathrm{CHD}$ both in diabetic and non-diabetic men.

The possible atherogenecity of insulin has been debated extensively the last few years [2,21-23]. There is experimental evidence favouring insulin as one of several causative factors in the development of atherosclerosis [2] but there is also a lack of consistency in epidemiological studies linking hyperinsulinaemia to clinically manifest atherosclerotic disease [21]. Apart from many case-control studies [2] only three prospective epidemiological studies [3-5] have reported an association between increased insulin levels and an increased risk of CHD in male subjects. The only study reporting on female subjects
[4] found no association between $1 \mathrm{~h}$ post-load insulin and the risk of CHD but for men in the same study there was a positive association. In the Helsinki Policemen Study [3] fasting blood glucose and plasma insulin did not predict CHD but 1 and 2-h post-load plasma insulin were independent risk factors for CHD in multivariate analyses. In the Paris Prospective Study [5] of male subjects aged 4354 years, an increased level of fasting insulin (but not increased blood glucose) was associated with an increased risk of CHD independent of the classic risk factors.

There is overwhelming evidence that diabetes is associated with a three-fold increased risk of CHD in men [6-9, $24,25]$ and four- to eight-fold increased risk of CHD in women [6,24-26]. Impaired glucose tolerance doubles the risk [9]. This is in agreement with our present report as well as with a previous report from this study [8] when the men were aged 50 at baseline and followed until the age of 67. Subjects with borderline hyperglycaemia who developed CHD were mainly those who became diabetic during the follow-up [8]. Whether diabetes causes atherosclerosis and CHD is less clear, it may well be that susceptible individuals have an increased risk of both diabetes and CHD [27].

In the diabetic group hyperglycaemia (or poor metabolic control) increased the risk of CHD. Although our sample of diabetic men is small this is in agreement with findings in Type 1 (insulin-dependent) diabetic patients that poor metabolic control increases the risk of complications [28]. Hyperglycaemia causes an increased non-enzymatic glycation of various proteins and lipoproteins [29] which leads to the formation and accumulation of advanced glycation end products with a permanently altered 
Table 3. Multiple logistic regression of risk factors for coronary heart disease among 67-year-old men followed for 8 years. All men including those with known diabetes

\begin{tabular}{|c|c|c|c|c|c|c|c|c|c|c|c|c|}
\hline \multirow[t]{2}{*}{ Risk factor } & \multicolumn{3}{|c|}{ Model 1} & \multicolumn{3}{|c|}{ Model 2} & \multicolumn{3}{|c|}{ Model 3} & \multicolumn{3}{|c|}{ Model 4} \\
\hline & Beta & SEM & $p$ & Beta & SEM & $p$ & Beta & SEM & $p$ & Beta & SEM & $p$ \\
\hline Serum cholesterol & 0.15 & 0.10 & 0.18 & 0.09 & 0.11 & 0.42 & 0.12 & 0.10 & 0.25 & 0.15 & 0.10 & 0.15 \\
\hline Fasting blood glucose & 0.19 & 0.08 & 0.01 & & & & & & & & & \\
\hline Blood glucose 1-h & & & & 0.00 & 0.07 & 0.98 & & & & & & \\
\hline Blood glucose 2-h & & & & 0.07 & 0.06 & 0.24 & & & & & & \\
\hline Fasting serum insulin & 0.00 & 0.01 & 0.45 & & & & 0.01 & 0.01 & 0.53 & & & \\
\hline
\end{tabular}

Beta, Regression coefficient. Diabetes was coded as; 0 , normal glucose tolerance; 1 , impaired glucose tolerance; 2 , newly-detected diabetes; 3 , known diabetes

function of cells, vessel walls and extracellular matrix. These changes might accelerate the atherosclerotic process which then causes the clinical end-point, CHD.

Acknowledgements. This study was supported by grants from the Swedish Medical Research Council (B90-27X-06276-09A), the Swedish Heart and Lung Foundation, the Göteborg Medical Society and the University of Göteborg.

\section{References}

1. Reaven GM (1988) Role of insulin resistance in human disease. Diabetes 37: 1595-1607

2. Stout RW (1990) Insulin and atheroma. 20-yr perspective. Diabetes Care 13: 631-659

3. Pyöräla K, Savolainen E, Kaukola S, Haapakoski J (1985) Plasma insulin as coronary heart disease risk factor: relationship to other risk factors and predictive value during 91/2 years followup of the Helsinki Policemen Study population. Acta Med Scand 701 [Suppl]: $38-52$

4. Welborn TA, Wearne K (1979) Coronary heart disease incidence and cardiovascular mortality in Busselton with reference to glucose and insulin concentrations. Diabetes Care 2:154-160

5. Eschwege E, Richard JL, Thibult N et al. (1985) Coronary heart disease mortality in relation to diabetes, blood glucose and plasma insulin levels. The Paris Prospective Study, ten years later. Horm Metab Res 15 (Suppl. series): 41-46

6. Jarrett RJ, McCartney P, Keen H (1982) The Bedford Survey: ten year mortality rates in newly diagnosed diabetics, borderline diabetics and normoglycaemic controls and risk indices for coronary heart disease in borderline diabetics. Diabetologia 22: 79-84

7. Rosengren A, Welin L, Tsipogianni A, Wilhelmsen L (1989) Impact of cardiovascular risk factors on coronary heart disease and mortality among middle aged diabetic men: a general population study. Br Med J 299: 1127-1131

8. Ohlson L-O, Svärdsudd K, Welin L et al. (1986) Fasting blood glucose and risk of coronary heart disease, stroke and all-cause mortality: a 17-year follow-up study of men born in 1913. Diabetic Med 3: 33-37

9. Fuller JH, Shipley MJ, Rose G, Jarrett RJ, Keen H (1980) Coronary-heart-disease risk and impaired glucose tolerance. The Whitehall Study. Lancet I: 1373-1376

10. Tibblin $G$ (1967) High blood pressure in men aged 50 - a population study of men born in 1913. Acta Med Scand 470 [Suppl]: 1-84

11. OhIson L-O, Larsson B, Eriksson H, Svärdsudd K, Welin L, Tibblin G (1987) Diabetes mellitus in Swedish middle-aged men. The study of men born in 1913 and 1923. Diabetologia 30: 386-393

12. Toeller M, Knusmann R (1973) Reproducibility of oral glucose tolerance tests with three different loads. Diabetologia 9: 102-107

13. Report of a WHO study group (1985) Diabetes mellitus. Technical Report Series 727. World Health Organization, Geneva, pp 10-14
14. WHO expert committee on diabetes mellitus (1980) Second Report. Technical Report Series 646. World Health Organization, Geneva

15. Olefsky J, Farquhar JW, Reaven G (1973) Relationship between fasting plasma insulin level and resistance to insulin-mediated glucose uptake in normal and diabetic subjects. Diabetes 22: 507513

16. Elmfeldt D, Wilhelmsen L, Tibblin G, Vedin A, Wilhelmsson CE, Bengtsson C (1975) Registration of myocardial infarction in the city of Göteborg, Sweden. J Chron Dis 28: 173-186

17. SAS Institute Inc. (1985) SAS user's guide: statistics, Version 5 Edition., SAS Institute Inc, Cary

18. Bradley JV (1968) Distribution-free statistical tests. Prentice Hall, London, pp 68-86

19. Foster DW (1989) Insulin resistance - a secret killer? N Engl J Med 320: 733-734

20. Welin L, Eriksson H, Larsson B et al. (1991) Triglycerides, a major coronary risk factor in elderly men. A study of men born in 1913. Eur Heart J 12: 700-704

21. Jarrett RJ (1988) Is insulin atherogenic? Diabetologia 31: 71-75

22. Orchard TJ (1988) Is insulin atherogenic? Diabetologia 31: 404 405 (Letter)

23. Gwinup G, Elias AN (1990) Insulin as a risk factor for vascular disease. Diabetes Care 13: 543-545 (Letter)

24. Panzram G (1987) Mortality and survival in type 2 (non-insulindependent) diabetes mellitus. Diabetologia 30: 123-131

25. Brand FN, Abbott RD, Kannel WB (1989) Diabetes, intermittent claudication, and risk of cardiovascular events. The Framingham study. Diabetes 38: 504-509

26. Lapidus L, Bengtsson $C$, Blohmé $G$, Lindquist $O$, Nyström $E$ (1985) Blood glucose, glucose tolerance and manifest diabetes in relation to cardiovascular disease and death in women. Acta Med Scand 218: 455-462

27. Jarrett RJ (1984) Type 2 (non-insulin-dependent) diabetes mellitus and coronary heart disease - chicken, egg or neither? Diabetologia 26: 99-102

28. Hanssen KF, Dahl-Jorgensen K, Lauritzen T, Feldt-Rasmussen B, Brinchmann-Hansen O, Deckert T (1986) Diabetic control and microvascular complications: the near-normoglycaemic experience. Diabetologia 29: 677-684

29. Brownlee M, Cerami A, Vlassara H (1988) Advanced glycosylation end products in tissue and the biochemical bases of diabetic complications. N Engl J Med 318: 1315-1321

Received: 28 January 1992

and in revised form: 21 April 1992

Dr. L. Welin

Department of Medicine

Östra Hospital

S-41685 Göteborg

Sweden 